\title{
Accelerated testing of track vehicle torsion bar
}

\author{
Jan Furch ${ }^{1, *}$, Quy Hung Nguyen ${ }^{2}$, Jiri Stodola ${ }^{1}$ \\ ${ }^{1}$ University of Defence in Brno, Faculty of Military Technology, 61200 Brno, Czech Republic \\ ${ }^{2}$ Institute of Mechanical Engineering, 122100 Hanoi, Vietnam
}

\begin{abstract}
The suspension system of track vehicles is often equipped with torsion bars. The torsion bar is a key element of the vehicle's suspension system. The service life of torsion bars depends primarily on the quality of the material used, the diameter of the torsion bars and the method of attachment and placement. In order to obtain the characteristics of the torsion bar, an experimental test stand was created on which accelerated tests were performed. Furthermore, a virtual model of torsion bar operation was created. The torsion bar was modelled using finite elements (FE part). Dynamic simulation was performed using MSC Adams software. Finally, the values measured in the accelerated tests and the results of simulations were compared. Comparing the values found, it was proved that this difference is not significant. This virtual model can be used to investigate the service life of torsion bars and to predict their service life.
\end{abstract}

\section{Introduction}

When test acceleration is accomplished with a single stress only, the models are life stress models, where the damage per unit time of the test is appropriately accelerated by increasing the level of stress.

The three most frequently used relationships are [1]:

a) inverse power law model, used for test acceleration when stresses other than constant temperature are considered, such as electrical, mechanical, chemical (corrosion) and others;

b) Arrhenius reaction rate model, used for constant temperature stresses, based on the effect that the absolute temperature has on a failure mechanism;

c) Eyring model which is used in cases where the acceleration is achieved with temperature and moisture stress levels. The model is derived from quantum mechanics.

With all acceleration models, test data can be analyzed using established analytical models to determine characteristic accelerated life parameters. Using the acceleration factors, the parameters corresponding to use environments are determined and used for reliability projections as needed. The acceleration models should, if possible, be verified by plotting the test data.

\section{Planning lifetime tests}

Planning lifetime tests can be divided into experimental-technical measurement planning and statistical test planning [2].

\subsection{Experimental-technical measurement planning}

The common fundamental principles for correct execution of an experiment apply. The most important of these principles is as listed the inverse power law is applicable to:

- The boundary conditions and limits must be exactly defined and kept.

- For lifetime tests this is especially important for the load spectrum.

- The technical measurement process for the registration and control of the boundary conditions must be established along with their accuracy. Depending upon the resources, more information is acquired at the test stand than actually needed.

- If longer testing times are expected, then the use of automated and/or computer controlled measured value gathering and control equipment should be strived for.

- For a determination of the lifetime, the exact specification of a limit value is necessary, at which the nominal function is no longer fulfilled. If the damage is a continuously changing value, as for example a leak volume for a seal.

- The control equipment must be built up in such a way that the primary failure cause can even be determined after the failure effect. This is important since each failure mode is assigned its own characteristic reliability parameters [2].

\subsection{Statistical test planning}

Accelerated life tests are component life tests with components operated at high stresses and failure data observed. Test planning means picking stress levels and sample sizes and test times to produce enough data to fit models and make projections. It is good design practice to put more of your test units in the lower stress cells, to make up for the fact that these cells will have a smaller proportion of units failing.

\footnotetext{
* Corresponding author: jan.furch@unob.cz
} 
In statistical test planning, the first step involves determining the size of the inspection lot. The inspection lot size is in close connection with the confidence levels and the statistical spread of the measured values. If fewer components are tested, then the result of the statistical assessment becomes more uncertain. For an accurate result, it is necessary that a sufficient quantity of components is tested. This can increase the time and effort involved in a test immensely. Fig. 1 shows the influence of number of test units on the reliability. It is obvious that with the diminishing of sample size, the reliability is decreasing.

Another important point in statistical test planning involves establishing a suitable test strategy. Possible strategies include:

a) complete tests,

b) incomplete (censored) tests,

c) strategies for shortening test times.

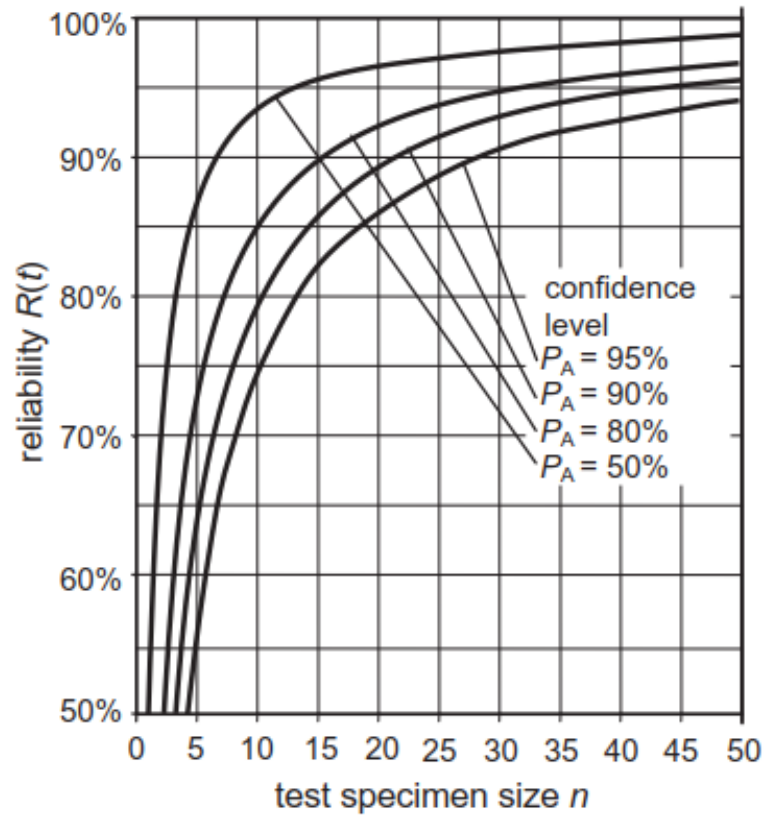

Fig. 1. Minimal reliability $R(t)$ as a function of the test specimen size $n$ and the confidence level $P_{A}$, if at the point in time $t$ no failure has occurred [2]

Another option for a considerably shorter test time is the Sudden Death Test and tests with an increased load. There are different types of accelerated life test (ALT) plans in use, which include subjective, traditional, best traditional, statistically optimum and compromise plans [3], [4], [5]. As with the simpler ALTs, evaluation of test plan properties can be done using either large-sample approximations or simulation methods [3].

Monte Carlo simulation provides a powerful, insightful tool for planning experiments. For a specified model and planning values for the model parameters, it is possible to use a computer to simulate ALT experiments to see the kind of data that will be obtained and to visualize the variability from trial to trial. Such simulations provide an assessment of sampling uncertainty that will result from using a limited number of test specimens [6].

\section{Theory planning accelerated life test}

Before starting an accelerated life test, it is advisable to have a plan that helps in accurately estimating reliability at operating conditions while minimizing test time and costs. To design the plan for the accelerated life tests it is necessary to establish the following parameters:

1 The acceleration model: For accelerated life tests where the failure mechanism is a mechanical one (the fatigue failure), the most adequate one is the IPL model. The inverse power law (IPL) model is commonly used for non-thermal accelerated stresses. This model was calculated by the formulas (1) - (3).

With the inverse power law, the characteristic that represents product reliability related to time, such as characteristic life, mean life, mean time to a failure, is represented as [1]:

$$
L(S)=C^{-1} \times S^{-m}
$$

where: $L(S)=$ is the life or other predetermined time duration as a function of stress; $C$ is one of the model parameters $(C>0)$ to be determined; $S$ represents the stress level; $m$ is another model parameter, dependent on stress behaviour, also to be determined.

The power law model is simple when expressed or plotted in logarithmic form, where it becomes a straight line with the slope representing the value of parameter $m$, and the value of the intercept with the $y$-axis is a function of the constant $S$ : (where the y-axis is the function)

$$
\ln [L(\mathrm{~S})]=-m \ln (S)-\ln (C) .
$$

The inverse power law is applicable to all distributions regularly used in reliability. The test acceleration factor is then:

$$
A_{S_{-} I P L}=\frac{L\left(S_{U s e}\right)}{L\left(S_{T e s t}\right)}=\frac{C^{-1} \times S_{\text {Use }}^{-m}}{C^{-1} \times S_{T e s t}^{-m}}=\left(\frac{S_{T e s t}}{S_{\text {Use }}}\right)^{m}
$$

where: $A_{S-I P L}$ is the acceleration factor of stress by inverse power law; $L\left(S_{U s e}\right)$ is the life as a function of stress in actual use; $L\left(S_{\text {Test }}\right)$ is the a function of stress applied in test.

Parameter $C$ in the test acceleration cancels out, but the parameter $m$ shall be determined for the item and the stress type. The parameter $m$ in the inverse power relationship is a measure of the effect of the stress on the life. As the absolute value of $m$ increases, so does the effect of the stress. Negative values of $m$ indicate an increasing life with increasing stress. An absolute value of $m$ approaching zero indicates small effect of the stress on the life, with no effect (constant life with stress) when $m=0$.

2 The available test time: Choose the duration of the accelerated life test 360000 cycles.

3 The number of units subjected to accelerated life tests: suppose 20 specimens.

4 The distribution law of the number of cycles until failure used in accelerated life testing: choose Weibull distribution and give shape parameter.

5 The stress under normal use condition and maximum in accelerated condition: the twist angle in normal condition is $30^{\circ}$ and the maximum angle is $50^{\circ}$ (during the experiment only $40^{\circ}$ ). 
6 The accelerated life test plan: choose three levels best compromise plan. This plan recommends three stress levels: a high stress level, which is the maximum allowable stress value that you specified during setup, a low stress level and a middle stress level.

The test plan was realized using the ALTA software, introducing the aforementioned parameters. The recommended test plan suggested stress levels to be used in the test and the recommended allocation of units to each stress level.

Table 1. Recommended test plan [1]

\begin{tabular}{|c|c|c|c|c|}
\hline $\begin{array}{c}\text { Stress } \\
\text { level }\end{array}$ & $\begin{array}{c}\text { Stress } \\
\text { value } \\
{\left[{ }^{\circ}\right]}\end{array}$ & $\begin{array}{c}\text { Unit } \\
\text { allocation } \\
{[\%]}\end{array}$ & $\begin{array}{c}\text { Unit } \\
\text { allocation } \\
{[\mathbf{Q} \text { ] }]}\end{array}$ & $\begin{array}{c}\text { Probability } \\
\text { of failure } \\
{[-]}\end{array}$ \\
\hline $\begin{array}{c}\text { Low } \\
\text { stress } \\
\text { level }\end{array}$ & 40 & 47.3 & 9.46 & 0.211 \\
\hline $\begin{array}{c}\text { Middle } \\
\text { stress } \\
\text { level }\end{array}$ & 45 & 25 & 5 & 0.648 \\
\hline $\begin{array}{c}\text { High } \\
\text { stress } \\
\text { level }\end{array}$ & 50 & 27.7 & 5.54 & 0.99 \\
\hline
\end{tabular}

The plan recommended 3 stress levels at $40^{\circ}, 45^{\circ}, 50^{\circ}$ and number of units for each stress level. That was 9 units to test at twist angle $40^{\circ}, 5$ units at $45^{\circ}$ and 6 units at $50^{\circ}$.

\section{Experiment description}

\subsection{Characteristics of torsion bar}

This chapter describes the practical implementation of the accelerated life test for the torsion bar of the combat track vehicle. The object of the test was a torsion bar of the track vehicle (thereafter called torsion bar). The section portrays the experimental test rig for imitating the operation of the torsion bar.

The suspension system of the track vehicle is designed to transfer the weight of the track vehicle through the track rollers and the track on the ground, to mitigate shocks and impacts acting on the track vehicle hull, and to quickly stop the hull oscillations. The quality of the suspension system to a large extent determines the average speeds of track vehicles on the ground, accuracy of fire on the move, crew performance, reliability and durability of the equipment of the track vehicle.

The track vehicle suspension system includes five suspension assemblies, each of which consists of a road arm, a torsion bar and a bumper. There are hydraulic absorbers on the first and fifth suspension assemblies. As a spring is used a torsion bar with a diameter of $52 \mathrm{~mm}$, made of 45ChNMFA steel, processed by grinding and shot peening, followed by prestressing. Chemical composition and mechanical properties of the torsion bar material are shown in the Table 2.

Table 2. Chemical composition and mechanical properties of the torsion bar material [6]

\begin{tabular}{|c|c|c|c|c|c|}
\hline $\mathbf{C}$ & $\mathbf{S}$ & $\mathbf{P}$ & $\mathbf{M n}$ & $\mathbf{C r}$ & $\mathbf{W}$ \\
\hline $0.42-0.50$ & $\leq 0.025$ & $\leq 0.025$ & $0.50-0.80$ & $0.80-1.10$ & $\leq 0.20$ \\
\hline
\end{tabular}

\begin{tabular}{|c|c|c|c|c|c|}
\hline $\mathbf{V}$ & $\mathbf{T i}$ & $\mathbf{S i}$ & $\mathbf{N i}$ & $\mathbf{M o}$ & $\mathbf{C u}$ \\
\hline $0.10-0.18$ & $\leq 0.030$ & $0.17-0.37$ & $1.30-1.80$ & $0.20-0.30$ & $\leq 0.30$ \\
\hline $\begin{array}{c}\text { UTS } \\
\text { MPa }\end{array}$ & $\begin{array}{c}\text { Yield } \\
\text { MPa }\end{array}$ & $\begin{array}{c}\text { Torsion } \\
\text { limit } \\
\text { MPa }\end{array}$ & $\begin{array}{c}\text { Shear } \\
\text { modulus } \\
\text { GPa }\end{array}$ & $\begin{array}{c}\text { Young's } \\
\text { modulus } \\
\text { GPa }\end{array}$ & $\begin{array}{c}\text { Hardness } \\
\text { HB }\end{array}$ \\
\hline 1384 & 1080 & 800 & 80 & 205 & 269 \\
\hline
\end{tabular}

\subsection{Test rig construction}

The test rig was built to test three torsion bars at three different twisting angles to determine the number of cycles to failure at every stress level. A complete test rig equipped with a complete measuring system has been designed and manufactured to measure the moment acting on torsion bar and the corresponding twist angle. The measured parameters are used to evaluate vehicle suspension characteristics. A lifetime of a torsion bar is predicted using the accelerated test in a fatigue test bench. Torsion bars involve repeated torsional loading. Torsional fatigue tests are performed on an axial-type machine. A typical torsional fatigue testing machine is shown in Fig. 2.

The test rig consists of a hydraulic power unit, hydraulic cylinder - actuator, and a controller. MTS SilentFlo ${ }^{\text {TM }}$ Hydraulic Power Unit 505.30 delivers superior performance in servo hydraulic testing applications. The MTS Model 493.02 FlexTest SE Controller made by MTS is a fully digital Proportional, Integral, Derivative, Feedforward (PIDF) servo controller. It provides complete control of one servo hydraulic channel or station in an MTS test system.

The swing angle of the road arm is measured by the Gyro Enhanced Inclinometer FAS-G of the MicroStrain, Inc. The FAS-G not only has the ability to measure static angles, but also dynamic, fast angular movements. Through the use of the two accelerometers and one piezoceramic gyro coupled with the requisite digital filtering and embedded software tracking algorithms, FAS-G provides dynamic response while maintaining the DC (static) measurement accuracy. As a result, during rapid angular movements, both the static and the dynamic components of the movement can be measured. The accuracy of the sensor is \pm 1 degree.

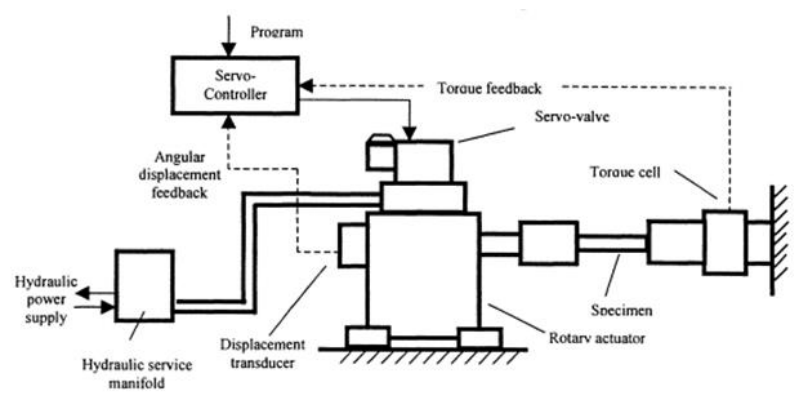

Fig. 2. Hydraulic torsional fatigue system [7]

A torsion bar was mounted on the test rig, one end was fixed, and the other end was connected with a swing arm, which rotated about the longitudinal axis of the torsion bar. The first torsion bar was twisted from $15^{\circ}$ to $25^{\circ}$ such as it operated in real life. Note that the static twist angle of the torsion bar is $14.8^{\circ}$. The second torsion bar was 
twisted from $15^{\circ}$ to $30^{\circ}$. The range of the third torsion bar was from $15^{\circ}$ to $40^{\circ}$. The first and the second torsion bars were swung with frequency $1.5 \mathrm{~Hz}$ while the third torsion bar was with frequency $1 \mathrm{~Hz}$. Every torsion bar went through more than 360000 cycles and no failure was observed. The experimental results are obtained after measuring the applied torque on the torsion bar and the corresponding twist angle.

Table 3. Twist angle and torque of torsion bar

\begin{tabular}{|c|c|c|c|c|c|}
\hline Twist angle, $\left[^{\circ}\right]$ & $\mathbf{1 5}$ & $\mathbf{2 5}$ & $\mathbf{3 0}$ & $\mathbf{4 0}$ & $\mathbf{5 3}$ \\
\hline $\begin{array}{c}\text { Twisting } \\
\text { moment, }[\mathrm{kNm}]\end{array}$ & 7.7 & 13.0 & 15.5 & 20.6 & - \\
\hline
\end{tabular}

\section{Model of torsion bar suspension}

While a track vehicle is travelling on road, it is subject to excitation from the road. Vertical motion of the road wheel causes the torsion bar to twist around its axis and is resisted by the bar's torsional resistance. The resistance of the torsion bar to twisting has the same effect as the coil spring used in conventional suspension systems.

From the model of torsion bar suspension as shown in Fig. 3, the vertical force exerted on the road wheel and transmitted through the axle arm to the torsion bar is determined by the formula [8]:

$$
P_{W}=\frac{G J}{L} \frac{\beta}{R \cos \left(\beta_{0}-\beta\right)}
$$

where $P_{w}$ - vertical force transmitted from road wheel to the hull; $G$-shear modulus of torsion bar material; $J$ - polar second moment of torsion bar cross-section $J=$ $\frac{\pi d^{4}}{32} ; d$ - diameter of torsion bar; $\beta$ - twist angle of torsion bar; $\beta_{0}$ - setting angle of torsion bar; $L$ - active length of torsion bar.

This force will cause a torsional moment acting on the torsion bar. The moment is correlated to the resulted twist angle $\beta$ by the following relationship [8]:

$$
T=P_{W} R \cos \left(\beta_{0}-\beta\right)
$$

therefore

$$
T=\frac{G J}{L} \beta=C \beta
$$

where $T$ - twisting moment on torsion bar; $R$ - radius of road wheel arm; $C$ - torsional stiffness of the torsion bar.

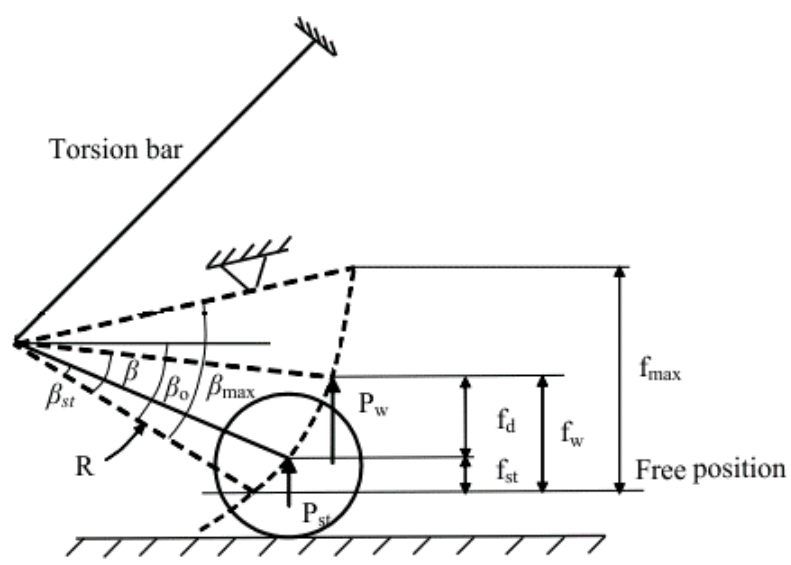

Fig. 3. Individual torsion bar suspension [8]

When a shaft is subjected to a torque or twisting, a shearing stress is produced in the shaft. The shear stress varies from zero in the axis to a maximum at the outside surface of the shaft. Shear stress $\beta$ in the torsion bar is given by:

$$
\tau=\frac{T}{J} r=\frac{G r}{L} \beta
$$

The torsional stiffness of a uniform rod is dependent on the cross-section diameter $\mathrm{r}$, the length $\mathrm{L}$, and the shear modulus $\mathrm{G}$ of elasticity of the rod. Hence, the torsion bar spring rate can be varied by appropriately changing any of the previous parameters [8].

In order to restrict the vertical travel of road wheel as well as safeguard the torsion bar, bumpers are welded on the track vehicle hull. Therefore, the twist angle of the torsion bar reaches the maximum value $\beta$ max when the swing arm touches the bumper. This angle is smaller than the one corresponding to the shear yield strength of the bar. On the track vehicle, this restrict angle accounts for $53^{\circ}$.

The static angle of the torsion bar $\beta$ st is approximately $14.8^{\circ}$. The static and maximum twist angles of the torsion bar can be calculated from the schema of individual suspension or measured provided that the setting angle is $\beta 0$.

The specifications of the individual torsion suspension are shown in the Table 4.

Table 4. Specifications of torsion bar suspension

\begin{tabular}{|l|c|}
\hline \multicolumn{1}{|c|}{ Parameters } & Values \\
\hline Torsion bar diameter, [mm] & 52 \\
\hline Torsion bar active length, [mm] & 1960 \\
\hline $\begin{array}{l}\text { Radius of road arm (swing arm), } \\
{[\mathrm{mm}]}\end{array}$ & 250 \\
\hline
\end{tabular}

\section{Test rig simulation}

In this article, the model of the test rig was built and tested using MSC Adams software. The virtual model allows simulating the torsion bar at the large twist angles that the test trig cannot. In this model, the torsion bar was represented by a 3D beam omprised of a single FE part of twelve nodes. One end is constrained with the ground and

\begin{tabular}{|c|c|c|c|c|c|}
\hline & \multicolumn{2}{|c|}{ Twist angle } & \multirow[b]{2}{*}{$\begin{array}{c}\text { Torque, } \\
\text { [kNm] }\end{array}$} & \multirow{2}{*}{$\begin{array}{l}\text { Shear } \\
\text { stress, } \\
\text { [MPa] }\end{array}$} & \multirow{2}{*}{$\begin{array}{l}\text { Equiv. } \\
\text { stress, } \\
\text { [MPa] }\end{array}$} \\
\hline & $\begin{array}{c}\text { angular } \\
{\left[^{\circ}\right]}\end{array}$ & [rad] & & & \\
\hline $\begin{array}{l}\text { Setting } \\
\text { position }\end{array}$ & 0 & 0 & 0 & 255 & \\
\hline $\begin{array}{l}\text { Static } \\
\text { angle }\end{array}$ & 14.8 & 0.258 & 7.6 & 276 & 21 \\
\hline $\begin{array}{l}\text { Static } \\
\text { angle }\end{array}$ & 25 & 0.436 & 12.9 & 466 & 211 \\
\hline $\begin{array}{l}\text { Static } \\
\text { angle }\end{array}$ & 30 & 0.524 & 15.4 & 559 & 304 \\
\hline
\end{tabular}
the other end is constrained with the swing arm.

Table 5. Values of twisting moment and shear stress at twist angle 


\begin{tabular}{|c|c|c|c|c|c|}
\hline & \multicolumn{2}{|c|}{ Twist angle } & \multirow[b]{2}{*}{$\begin{array}{c}\text { Torque, } \\
\text { [kNm] }\end{array}$} & \multirow{2}{*}{$\begin{array}{l}\text { Shear } \\
\text { stress, } \\
\text { [MPa] }\end{array}$} & \multirow{2}{*}{$\begin{array}{l}\text { Equiv. } \\
\text { stress, } \\
\text { [MPa] }\end{array}$} \\
\hline & $\begin{array}{c}\text { angular } \\
{\left[^{\circ}\right]}\end{array}$ & [rad] & & & \\
\hline $\begin{array}{l}\text { Static } \\
\text { angle }\end{array}$ & 40 & 0.698 & 20.6 & 745 & 490 \\
\hline $\begin{array}{l}\text { Static } \\
\text { angle }\end{array}$ & 45 & 0.785 & 23.1 & 838 & 583 \\
\hline $\begin{array}{l}\text { Static } \\
\text { angle }\end{array}$ & 50 & 0.873 & 25.7 & 931 & 676 \\
\hline $\begin{array}{l}\text { Strict } \\
\text { angle }\end{array}$ & 53 & 0.934 & 27.5 & 996 & 741 \\
\hline
\end{tabular}

The FE part is a wholly Adams-native modelling object with inertia properties and is accurate for very large deformation cases of beam-like structures. The FE part differs from the linear flexible body option within Adams Flex in two significant ways. Firstly, it has the ability to accurately represent large deformations which the linear modes approach cannot. Secondly, its modelling does not require an FEA produced file like the modal neutral file.
The FE Part also differs from the beam force element in that it possesses inertia properties [9].

For the test rig model and through the experiment, the following data were applied: torsion bar diameter - $52 \mathrm{~mm}$, torsion bar active length - $1960 \mathrm{~mm}$, shear modulus of torsion bar material $-80.23 \mathrm{kN} / \mathrm{mm}^{2}$.

Table 6. Comparison of experimental and simulation results

\begin{tabular}{|c|c|c|c|c|c|c|}
\hline \multicolumn{2}{|c|}{ Twist angle in $\left[^{\circ}\right]$} & $\mathbf{1 5}$ & $\mathbf{2 5}$ & $\mathbf{3 0}$ & $\mathbf{4 0}$ & $\mathbf{5 3}$ \\
\hline \multirow{2}{*}{$\begin{array}{c}\text { Twisting } \\
\text { moment } \\
\mathrm{kNm}\end{array}$} & $\begin{array}{l}\text { Experiment } \\
{[\mathrm{kNm}]}\end{array}$ & 7.7 & 13.0 & 15.5 & 20.6 & - \\
\cline { 2 - 7 } & $\begin{array}{l}\text { Simulation } \\
{[\mathrm{kNm}]}\end{array}$ & 7.6 & 12.7 & 15.2 & 20.3 & 26.9 \\
\hline
\end{tabular}

It is clear from the table that the results of physical tests and simulation have an insignificant difference.

Created model make possible to simulate the dynamic analysis, obtained the twist angle and the torque of torsion bar and compare to the real test results. The comparison is shown in the Table 6.

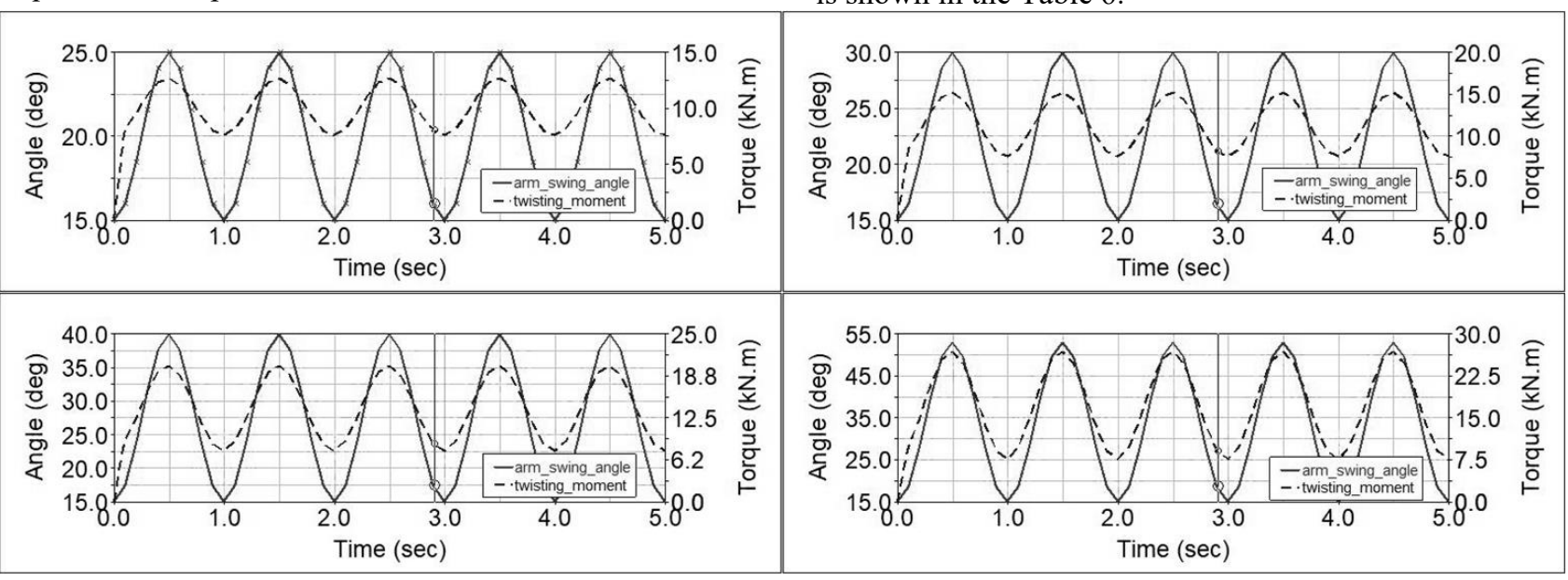

Fig. 4. Simulation results for twisting moment and swing angle of road arm

\section{Conclusion}

This article deals with the accelerated life test for a torsion bar of the track vehicle. Majority of mechanical damages of structural elements occur due to material fatigue during its normal operation. Fatigue is a major failure mechanism of mechanical parts. At the same time, this type of damage is considered to be the most dangerous one, the crack initiation in structural elements is difficult to predict, and it leads to damage of the elements.

The primary purpose of an ALT is to estimate the life distribution and quantities of interest in a use condition. This estimation involves extrapolation from higher stress levels by using an acceleration model and thus includes the model error and statistical uncertainty.

For the torsion bars of tracked combat vehicles with stringent functionality specifications, the reliability is very high. Therefore, their life testing under nominal conditions requires much time and resources. In response to this problem, ALT finds an application to obtain timely information on the reliability of the products.
[1] IEC 62506: Methods for Product Accelerated Testing. (2003)

[2] B. Bertsche, Reliability in Automotive and Mechanical Engineering - Determination of Component and System Reliability. (Springer, 2008)

[3] W. Q. Meeker, L. A. Escobar, Statistical Methods for Reliability Data. (Wiley, 1998)

[4] W. B. Nelson, Accelerated Testing - Statistical Models, Test Plans, and Data Analysis. (Wiley, 2004)

[5] G. Yang, Life Cycle Reliability Engineering. (Wiley, 2007)

[6] B. Leitner, L. Figuli, Fatigue life prediction of mechanical structures under stochastic loading. 157. (EDP Sciences, Les Ulis, 2018)

[7] ASM International. Handbook Vol. 8: Mechanical Testing. The Materials Information Society. (1996)

[8] L. V. Sergeev, Theory of tank. Academy BTV Press, Moscow, 1973.

[9] Mechanical dynamics. Building Models in ADAMS/View. (Ann Arbor, Michigan, 2000)

\section{References}

